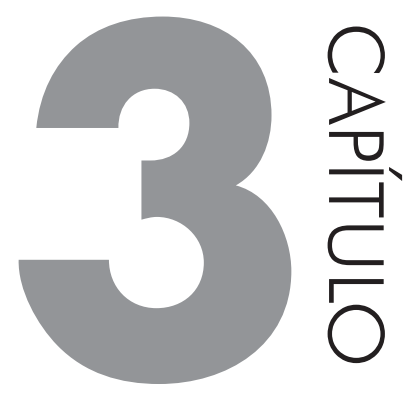

\title{
TEMPO DE LEITURA, TEMPO DE AULA E MOTIVAÇÃO
}

Apresentamos, a seguir, os resultados dos estudos realizados, com o objetivo de verificar efeitos do tempo social e do tempo cognitivo na aula de língua inglesa para alunos envelhescentes e da terceira idade.

\subsection{TEMPO DE LEITURA}

No experimento de tempo de leitura, utilizamos os parâmetros de sacadas, fixações e regressões em três categorias: jovens, envelhescentes e pessoas da terceira idade. A realização de leituras de textos com cerca de aproximadamente 100 palavras, sendo dez textos em inglês e dez textos em português, permitiu que fosse medido o tempo entre as sacadas, fixações e regressões e que tivéssemos um padrão de tempo de leitura para as categorias jovens, envelhescentes e pessoas da terceira idade.

Quanto à regressão, imagina-se que, com a utilização de estratégias de leitura, os participantes façam um maior número de regressões na tentativa de compreender o texto. Conforme Frazier e Rayner (1982), Altmann, Gamham, Dennis (1992) e Rayner e Sereno (1994), 15\% de regressões em um total de sacadas são encontrados nas circunstâncias normais de leitura. Rayner (1998) comparou o processamento de leitura em diferentes condições e os textos identificados como 
de fácil leitura são aqueles que apresentam o menor número de regressões; em condições mais difíceis, o número de regressões aumenta. Assim, em termos de duração, o tempo de leitura em condições de dificuldades (região central, com e sem presença de conectivo) é maior do que em condições mais fáceis.

Quanto à duração das sacadas, a frequência de ocorrência de sacadas e não sacadas fará com que os números fiquem relacionados a área (região) na qual a medida do tempo de leitura será aplicada. Por isso, se houver a dificuldade do processamento, o número de fixações na região aumentará. O tamanho do texto também influencia na duração do tempo de sacadas, segundo Rayner (1998).

Apresentados os parâmetros, passemos à análise do tempo de leitura silenciosa e em voz alta.

\subsubsection{Leitura silenciosa e em voz alta}

Nos estudos de uma língua estrangeira, entendemos ser importante o reconhecimento inicial das palavras em leitura silenciosa e posteriormente em leitura em voz alta para que os aprendizes de uma língua estrangeira possam ter a oportunidade de ouvir o som e experienciar a sua verbalização. Dehaene (2012) descreve as duas vias de leitura simultâneas:

[...] dispomos todos de uma via direta de compreendê-los. Contudo, nos leitores experientes, a sonoridade das palavras continua a ser utilizada [...] a nível mais profundo do nosso cérebro, as informações sobre a pronúncia das palavras são automaticamente ativadas. As duas vias de tratamento das palavras, a via lexical e a via fonológica, funcionam, em paralelo, uma sustentando a outra. (DEHAENE, 2012, p. 40)

$\mathrm{Na}$ leitura em voz alta, o leitor deve proceder a duas tarefas simultâneas. Ele deve proceder a uma linguagem oral equivalente à linguagem escrita e ele deve também reconstruir o significado do que ele está lendo, ou seja, procurando compreender a leitura. O leitor reconhece a codificação gráfica como uma linguagem fonológica oral. Esse processamento da leitura pode ser aprendido por alguém que não fale a língua, mas que pode ser memorizada e posteriormente verbalizada, como uma música. Mas o leitor, ao analisar a linguagem semântica, pode reconstruir o significado da linguagem escrita e assim compreender a decodificação.

Esses processos de decodificação de leitura devem ser automatizados ou bem assimilados e até mesmo autônomos. No ensino de uma língua estrangeira, o processamento de ensinar a decodificar é semelhante. Embora o conhecimento da primeira língua já esteja internalizado, o novo aprendiz executa o processamento 
de aprendizagem de uma língua estrangeira no modelo similar, com diferentes perspectivas de desenvoltura.

Embora os participantes façam movimentos de retorno de leitura e fixação mais demorados, possivelmente para compreender melhor o que leram, evidenciando o nível da acurácia, o objetivo do experimento, tanto da leitura silenciosa quanto em voz alta é identificar o tempo de duração da leitura, sem necessariamente aferir a compreensão.

As hipóteses para o controle do tempo de leitura são:

- Todos os participantes são mais rápidos na leitura de textos em português do que de textos em inglês.

- Todos os participantes são mais rápidos na leitura silenciosa do que em voz alta.

- Participantes mais jovens demandam menos tempo do que os participantes envelhescentes, que, por sua vez, demandam menos tempo do que os participantes da terceira idade na execução dessas tarefas.

\section{$\boxminus$ Leitura Voz Alta $\boxminus$ Leitura Silenciosa}

(A)

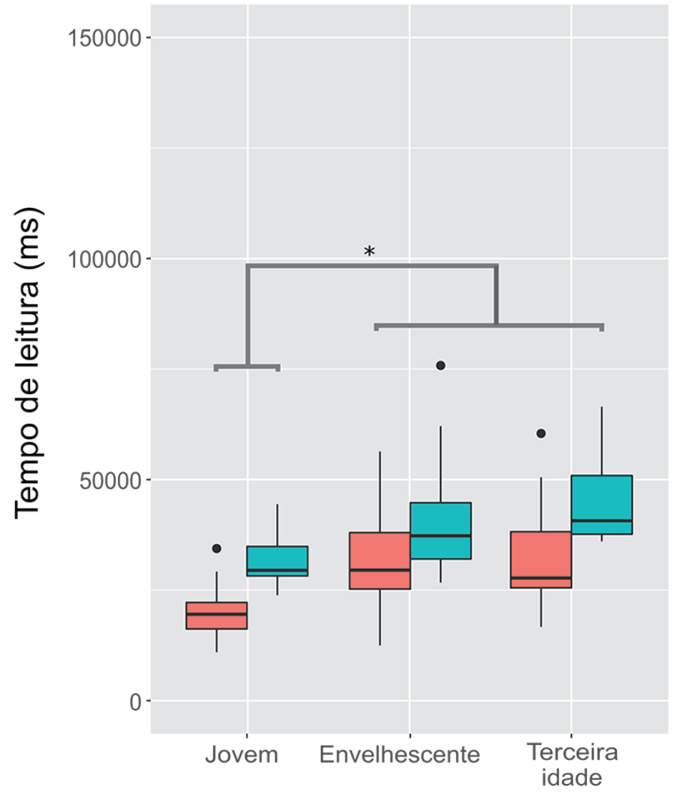

(B)

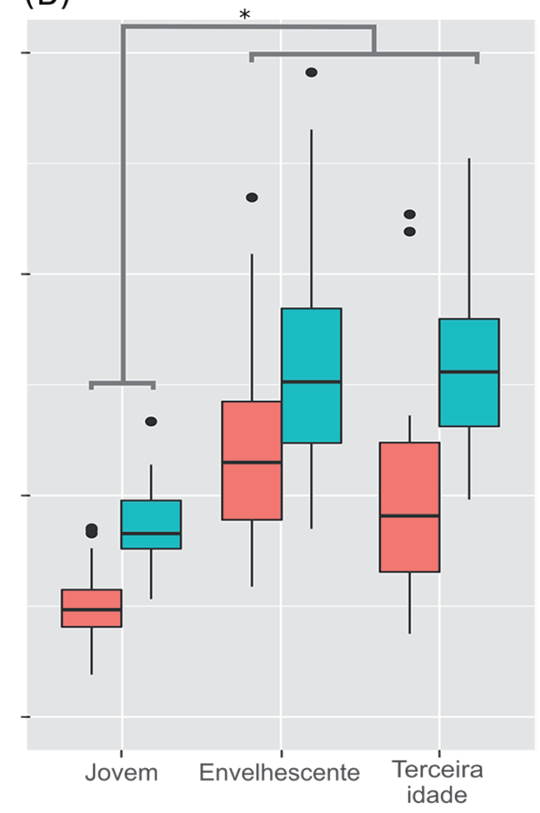

Grupos experimentais

Gráfico 3 Desempenho dos grupos experimentais quanto ao tempo de leitura em voz alta e silenciosa, em textos em (A) português e em (B) inglês 
O Gráfico 3 apresenta os resultados do tempo médio de leitura dos textos em inglês e em português, em voz alta e silenciosa, quanto aos três grupos experimentais: jovens, envelhescentes e pessoas da terceira idade. O que podemos notar é que o tempo médio de leitura entre as categorias envelhescentes e terceira idade são semelhantes (tanto em português quanto em inglês) e maiores do que apresenta a categoria jovem, nas leituras silenciosas e em voz alta ([ANOVA para os textos em Português: $\mathrm{F}_{(2,176)}=38,71, \mathrm{P}<0,001 \mathrm{~F}_{(1,176)}=66,63, \mathrm{P}<0,001$ ]; [ANOVA para os textos em Inglês: $\left.\left.\mathrm{F}_{(2,175)}=67,10, \mathrm{P}<0,001 ; \mathrm{F}_{(1,175)}=41,48, \mathrm{P}<0,001\right]\right)$ $\mathrm{O}$ grupo de participantes jovens se diferenciou dos outros dois grupos significativamente para ambas as línguas, conforme resultado de um teste ANOVA de duas vias: grupo e tipo de leitura.

Nos textos em inglês, o tempo de leitura de todos os participantes foi maior do que nos textos em português. No entanto, alguns dos participantes tiveram um comportamento fora do padrão estabelecido, o que pode ser observado pela presença marcante da linha vertical, como pode ser verificado no Gráfico 3).

O resultado permite afirmar que houve diferenças entre os grupos. As hipóteses sobre o tempo de leitura de envelhescente e pessoa da terceira idade ser maior do que a leitura de um jovem se confirmam diante dos dados apresentados: nos textos em português, a terceira idade necessita de mais tempo do que as demais categorias mostrando uma variação. No entanto, os envelhescentes parecem gastar mais tempo do que os membros do grupo da terceira idade, não obstante essa diferença não seja significativa. Vale ressaltar que os jovens obtiveram sua leitura no tempo padrão entre 200 a 250 ms.

A leitura silenciosa demonstra menor tempo do que a leitura em voz alta devido à preocupação do leitor em pronunciar os fonemas adequados de acordo com os traços fonológicos da língua. O tempo de leitura silenciosa é menor devido à não preocupação da pronúncia sobre as palavras. Nos textos em inglês, o tempo foi muito maior. Os participantes da terceira idade apresentaram um tempo muito maior equivalente a aproximadamente $500 \mathrm{~ms}$ enquanto que, para a leitura em voz alta, aproximadamente 600 a 650 ms. Já para os envelhescentes, o tempo foi superior ao tempo gasto pela terceira idade, o que demonstra uma dispersão do tempo de leitura. Já os envelhescentes apresentaram maior dispersão no registro do tempo das tarefas executadas como os participantes da terceira idade, a exemplo do resultado da leitura silenciosa (está aproximadamente a 600 a 700 $\mathrm{ms}$ ) para a leitura em voz alta eles também apresentam tempos muito maiores do que a terceira idade (com aproximadamente $200 \mathrm{~ms}$ ), embora não seja uma diferença significativa.

A diferença de tempo encontrada entre os grupos experimentais confirma a hipótese levantada. No entanto, convém destacar que o tempo de diferença de leitura entre os grupos de envelhescentes e de pessoas da terceira idade em relação 
aos mais jovens está na casa de milissegundos. Essa diferença pode ser crucial, por exemplo, para a concessão de carteira de habilitação (na medida em que, em milissegundos de diferença, podem causar um acidente de trânsito), mas em uma aula de 60 minutos, por exemplo, embora essa diferença exista, comprovando o que a literatura aponta quanto ao aumento da demanda de tempo na execução de tarefas, os milissegundos de diferença não interferem na aula de inglês. Esse resultado é importante para desmistificar o fato de que "idosos" são mais lentos e que por isso teriam dificuldades de aprender ou precisariam de mais tempo para executar atividades de leitura (eles precisam, mas o tempo demandado não influencia no conjunto geral de uma aula).

\subsubsection{Número de fixações}

A hipótese para o controle da variável fixações é de que participantes do grupo experimental mais jovem fazem menos fixações (com sacadas mais longas) do que os participantes envelhescentes, que, por sua vez, façam menos fixações do que os participantes da terceira idade, em função das limitações fisiológicas do envelhecimento (enrijecimento da musculatura).

\section{$\boxminus$ Leitura Voz Alta $\boxminus$ Leitura Silenciosa}

(A)

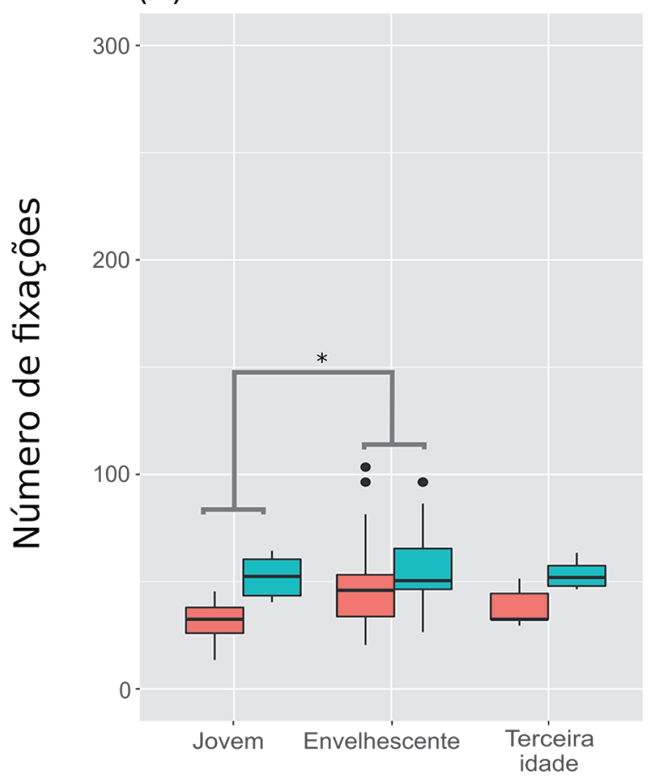

(B)

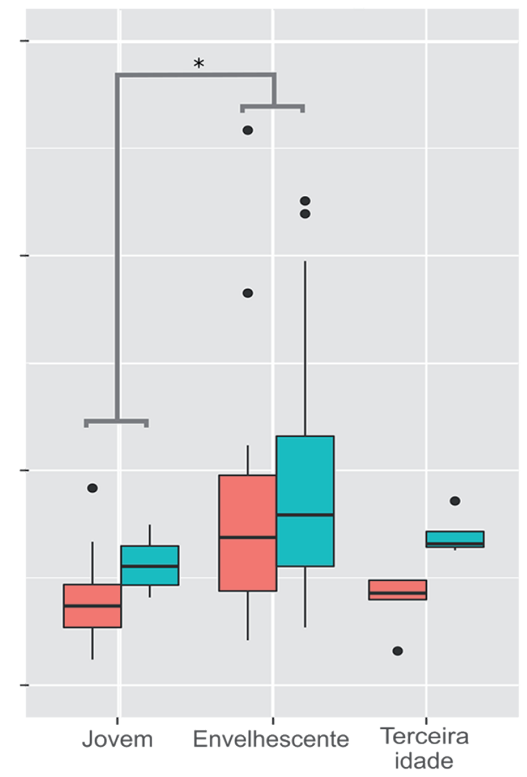

Grupos experimentais

Gráfico 4 Desempenho dos grupos experimentais quanto ao número de fixações, em textos em (A) português e em (B) inglês 
No Gráfico 4, identificamos que houve diferença entre os grupos de jovens e envelhescentes, corroborando parcialmente a hipótese levantada. O grupo da terceira idade obteve um número de fixações menor do que o dos envelhescentes, que obtiveram um número bastante acentuado de fixações. A realização de um teste ANOVA de duas vias, grupo e tipo de leitura, apontou que só os grupos de participantes jovens e envelhescentes tiveram diferenças significativas no número de fixações ([ANOVA para os textos em Português: $\mathrm{F}_{(2,122)}=10,70, \mathrm{P}<0,001$; $\left.\mathrm{F}_{(1,122)}=24,12, \mathrm{P}<0,001\right] ;$ [ANOVA para os textos em Inglês: $\mathrm{F}_{(2,121)}=9,827, \mathrm{P}<$ 0,$\left.\left.001 ; \mathrm{F}_{(1,121)}=1,345, \mathrm{P}>0,05\right]\right)$.

Nas análises dos dados apresentados, podemos estabelecer um padrão de 68,5 palavras nos textos em português, com uma mediana de 68,0 e um desvio padrão de 10,0. Já nos textos em inglês, a média de palavras foi de 82,9 , a mediana de 79,5 e o desvio padrão de 16,5 .

Podemos observar no Gráfico 4 que, quanto aos participantes em relação aos grupos experimentais jovens, envelhescentes e pessoas da terceira idade, as fixações foram mais executadas pelos envelhescentes do que pelos participantes da terceira idade. Já os jovens obtiveram menor número de fixações. Esse resultado só permite afirmar que houve diferenças entre os grupos; um grupo mostrou um número de fixação menor que o outro. Lembramos que não estamos analisando compreensão de leitura e sim o tempo da leitura. A linha vertical mostra que houve uma diferença muito maior entre os membros das mesmas categorias.

Rayner (1998) aponta que até mesmo os leitores hábeis fazem regressões diante de algumas dificuldades da língua, como em estruturas de frases mais elaboradas. Leitores em geral fazem mais fixações, menos sacadas e mais regressões. Os leitores costumam pular, traçar, omitir palavras durante a leitura de textos, mas, mesmo assim, no contexto, isso não é prejudicial. A duração da fixação na palavra pode trazer significações de interpretação sobre palavra, contexto, tempo, sintaxe. Adicionamos também o fator escolaridade e habitualidade de leitura, que são informações relevantes que poderiam ser observadas.

Embora os estudos de Vonk, Cozjin (2003), Rayner, Chace e Slattery (2006) sugiram que os leitores façam a compreensão do texto durante a leitura, eles também alertam para as várias intercorrências sobre o movimento ocular, que refletem, no tempo de fixação, o processo dos leitores em obter significado. Outra observação pode estar relacionada ao estado emocional de cada pessoa, assim 
como também toda a preparação antecedente aos experimentos, tais como óculos, maquiagem, transplante das córneas ou catarata.

O fato de envelhescentes e pessoas de terceira idade realizarem mais fixações para a leitura aponta para a necessidade de se considerar esse fator na hora de desenvolver materiais didáticos de suporte à leitura, com uma diagramação que permita movimentos confortáveis de sacadas (mancha da página mais estreita, por exemplo).

\subsubsection{Duração das fixações}

Quando as questões de experimentos focalizam na sentença ou no processamento de uma palavra, o primeiro passo do tempo da leitura definirá um número de fixações que deverão ser medidos para se obter um tempo de leitura.

Quando lemos, olhamos as cenas, ou a procura por um objeto, continuamente fazemos esse movimento ocular chamado de sacadas, entre as sacadas, nossos olhos permanecem relativamente ainda durante as fixações por 200-300 ms por segundos. Em leitura silenciosa, a duração de fixação é (225 ms -2 sacadas-8 letras); leitura oral ( $275 \mathrm{~ms}$. -1.5 sacada -6 letras); percepção visual ( 275 ms, 3 sacadas); percepção de uma cena $(330$ ms, 4 sacadas); leitura de uma música ( 375 ms, 1 sacada); digitação (400 ms 1 sacada, 4 letras). (RAYNER, 1998, p. 373, radução nossa) ${ }^{1}$

As fixações mostram que os leitores estão à procura de compreensão sobre a palavra ou frase. O movimento sacádico dura em torno de 30 a $50 \mathrm{~ms}$, com uma amplitude média de 7 a 9 espaços de letras; a fixação dura em média 200 a 250 ms (leitor não hábil).

Do mesmo modo que, para o número de fixações, a hipótese para o controle dessa variável é de que participantes do grupo experimental mais jovem fazem fixações com maior duração do que os participantes envelhescentes, que, por sua vez, fazem fixações com maior frequência do que os participantes da terceira idade.

1 When we read, look at a scene, or search for an object, we continually make eye movements called saccades. Between the saccades, our eyes remain relatively still during fixations for about 200-300 ms... Saccades are rapid movements of the eyes with velocities as high as $500^{\circ}$ per second. For Silent reading (225 ms. 2 - saccades - 8 letters); Oral reading 275 ms. (1.5 saccades 6 letters); Visual search 275 ms. (3 saccades); Scene perception 330 ms. (4saccades); Music reading 375 ms. (1 saccade); Typing $400 \mathrm{~ms}$. (1 saccade). 373 p. $2^{\circ} \$$. 


\section{$\boxminus$ Leitura Voz Alta $\boxminus$ Leitura Silenciosa}

(A)

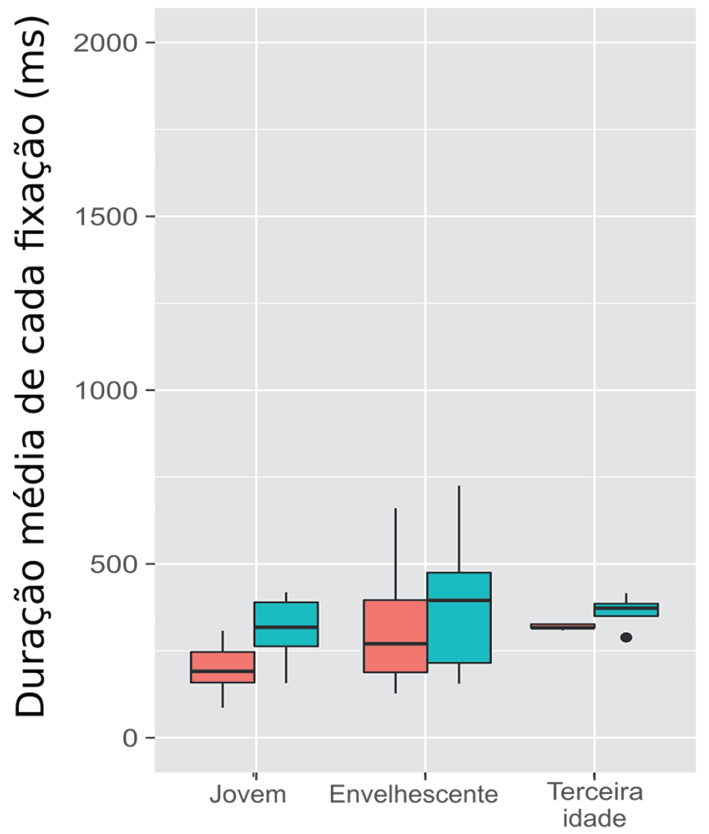

(B)

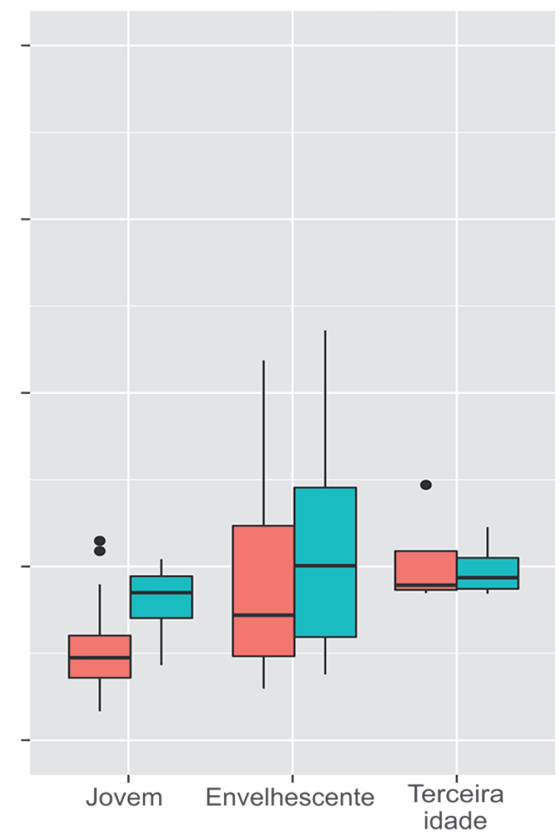

\section{Grupos experimentais}

Gráfico 5 Desempenho dos grupos experimentais quanto à duração média das fixações, em textos em $(A)$ português e em (B) inglês

No Gráfico 5, apresentamos o quadro comparativo de duração média da fixação em ms de dezenove participantes. Ao observar na leitura em inglês, entre as categorias jovens, envelhescentes e da terceira idade, os envelhescentes apresentaram uma duração média maior que as outras duas categorias; contudo, as diferenças não são significativas, o que não corrobora a hipótese da perda de acurácia, devido à idade ([ANOVA para os textos em Português: $\mathrm{F}_{(2,122)}=0,17, \mathrm{P}=$ 0,$844 ; \mathrm{F}_{(1,122)}=0,403, \mathrm{P}=0,527$ ]; [ANOVA para os textos em Inglês: $\mathrm{F}_{(2,121)}=$ $\left.\left.0,960, \mathrm{P}=0,386 ; \mathrm{F}_{(1,121)}=1,117, \mathrm{P}=0,293\right]\right)$.

\subsubsection{Movimentos oculares}

Segundo Dehaene (2012), um bom leitor deve filtrar e ou rejeitar as variações que não sejam pertinentes à leitura. Ressalta ainda sobre o saber preservar e ampliar os detalhes das funções da língua (muitas vezes palavras minúsculas se diferenciam de palavras próximas, com distinção apenas de morfemas seme- 
lhantes). A duração da fixação demorada é definida como a somatória das fixações na palavra até vir a seguinte em uma nova direção. A medida foi inicialmente utilizada por Just e Carpenter (1980), para indicar que o tempo de leitura era associado ao processamento de uma palavra.

Encontros consonantais, palavras desconhecidas, números ordinais e ou cardinais afetam o olhar do leitor para fazer a captura da decodificação da palavra em relação a entoação, ritmo, tempo de leitura (RAYNER, 1998). Nesse sentido, esses aspectos linguísticos dos sons da língua atuam durante a leitura e influenciam a predibilidade da leitura do texto tendo muitas vezes que fazer o go-past (retorno-de-leitura) e consequentemente afetando o tempo na leitura.

Estudos indicam que as variáveis como frequência (INHOFF; RAYNER, 1986; RAYNER; DUFFY, 1988), previsão (EHRLICH; RAYNER，1981; RAYNER; WELL, 1996) e a idade de aquisição de uma palavra (JUHASZ; RAYNER, 2003, 2006) influenciam fortemente sobre o tempo de fixação na palavra. O movimento ocular reflete as dificuldades que os leitores menos hábeis têm em decodificar as palavras e entender o texto. Palavras simples (monomorfêmicas), como artigo, preposição, conjunção não trazem significado ao texto, enquanto palavras compostas (morfêmicas), como verbo, adjetivo, trazem significações ao texto. Se os leitores sempre fazem uma sacada e uma fixação em cada palavra, então a média de duração da fixação refletiria no processamento do tempo da palavra.

$\mathrm{Na}$ realidade, alguns leitores pulam palavras (cerca de dois terços das palavras são tipicamente fixadas, palavras curtas e palavras previsíveis sempre são puladas) e algumas vezes os leitores fazem mais do que uma fixação em uma palavra antes de mover para outra palavra. Assim sendo, quando as questões de experimentos focalizam em um processamento de palavras simples, os pesquisadores de movimento ocular reportam tipicamente um número de relações de medidas para capturar o tempo do processamento da palavra, assim como a duração das primeiras fixações (a duração da primeira fixação na palavra), a duração de fixação simples (casos quando apenas uma fixação é feita na palavra), a duração de olhar fixante gaze-duration (a soma de todas as fixações sobre a palavra anterior em movimento para uma outra palavra) e o tempo total de fixação (soma de todas as fixações, incluindo regressão na palavra). Complementarmente, a probabilidade de fixação na palavra e a frequência de regressões fora da palavra são também reportadas (VONK; COZIKN, 2003).

A hipótese para o controle dos movimentos oculares considera que as dificuldades dos discursos global ou local aumentam as durações de fixações assim 
como o número das fixações e a probabilidade de regressões durante a leitura silenciosa de longas passagens do texto. Esse argumento tem sido evidenciado em experimentos de reconhecimento de palavras e processamento de sentenças, contudo a extensão de qual é a dificuldade que geralmente afeta o movimento ocular é menos clara (RAYNER, 1998).

Nesse sentido, foram feitas leituras com marcação do tempo para verificar quanto tempo os envelhescentes levam para fazer o processamento da leitura com uso da ferramenta em eye-tracking e qual a diferença de tempo será estabelecida para obtermos o tempo de leitura para os participantes da terceira idade. Hipoteticamente sabemos que os participantes da terceira idade são mais lentos devido às suas perdas cognitivas decorrentes da idade que fazem com que, com o decorrer do tempo, naturalmente, eles diminuam as suas agilidades e, fisiologicamente, os músculos e plasticidade já se mostrem diferentes. Por isso, foram feitas análises em relação às regressões, fixações e sacadas que traduzem outras interpretações, chamadas de características básicas do movimento ocular.

Quando as questões de experimentos focalizam na sentença ou no processamento de uma palavra, o tempo da leitura (a somatória de todas as fixações na região) é computado. Uma medida adicional é a do tempo de regressão (go-past), a soma de todos as fixações da primeira leitura a entrar em uma região até a saída na direção linear (forward). Essa medida também é chamada de duração de trajetória de regressão e inclui qualquer regressão fora da região anterior para o deslocamento da leitura seguinte (forward) no texto; quais medidas são mais úteis ao analisar o dado, que pode variar de um estudo geral para um mais específico. Entendemos que os autores demonstraram as possibilidades de interpretação de leitura do texto no movimento ocular em relação a sacadas, fixações, regressões. Vonk e Cozijn (2003) e Rayner, Chace e Slattery (2006) apontam fatores que desencadeiam dificuldades de leitura, tanto para o leitor hábil como menos hábil, como palavras que contenham informações numéricas, encontros consonantais, palavras homófonas, etc.

Assim, com o ato da repetição das regressões dos leitores, para uma região anterior do texto, o leitor busca compreender o que ele não entendeu anteriormente fazendo regressões, assim como também deve ser observado o número de vezes de fixações para regiões anteriores do texto ou início do texto.

A duração da primeira fixação na palavra (região) reflete o processamento de dificuldade do leitor. Elas mostram os efeitos de frequência de palavra. Essa medida é menos usada se a região da visão for menor. Um campo maior requer mais fixações para serem processadas. Então a primeira indicação de fixação 
não será o indicado para completar o processamento da região do campo de visão.

A seguir, apresentamos dois textos/testes-pilotos em inglês. O participante teve que ler em voz silenciosa e ou em voz alta (dependendo da ordem apresentada no experimento).

\begin{abstract}
l've always wanted to be able to dance salsa, and when I was working in Ecuador there were free classes, so I joined: But the art of salsa is to keep your arms still and move your hips; and I just couldn't do it. When I hear music my arms start moving but my hips dont't.
\end{abstract}

Figura 7 Texto 1 - piloto leitura silenciosa em inglês

Fonte: Dados de pesquisa.

\begin{abstract}
Would you like to live in a beautiful house in the heart of the Canadian Rocky Mountaîns? It's spacious house with four bedrooms, a living room, a large kitchen, two bathrooms, and a store room. It has a large balcony, which is ideal for eating outside iñ the sümmer. The house has wooden floors, a jacuzzi, cable televisjon, and internet. It's quiet, safe neighbourhood and the neighbours are very warm and friendty. This house is perfect for families or two couples. It's a no smoking house and, sorry, no pets.
\end{abstract}

Figura 8 Texto 3 - piloto leitura silenciosa em inglês

Fonte: Dados de pesquisa.

Apresentamos também dois textos/testes-pilotos em português. O participante teve que ler em voz silenciosa e ou em voz alta (dependendo da ordem apresentada no experimento). 


\begin{abstract}
A língua é um fato social e veicula, além de informaçõęs referenciais, também significados sociais, eśtilisticos e culturais, expressos em modos de ação dos interlocutores refletidos em diferentes funções da linguagem. Quando falamos, exteriorizamos nossos pensamentos, sentimentos, atitudes e também revelamos a nossa identidade social e regional, envolvendô fatores refletidos nas relaç̧̃̃es sociais entre os participantes de uma situação comunicativa.
\end{abstract}

Figura 9 Texto 1 - piloto leitura silenciosa em português

Fonte: Dados de pesquisa.

Para fins de testagem, o texto deve ser centralizado para facilitar a área de leitura que o participante deve ler. O objetivo da leitura foi calcular o tempo de leitura. Palavras comuns, como preposição, conectivo e artigos são as palavras que não trazem significados de palavras e muitas vezes os olhos pulam a leitura, enquanto que palavras complexas são aquelas que mais tendem a receber as fixações. Os participantes, em geral, não apresentaram problemas de leitura nos textos em português.

\footnotetext{
É da natureza humana viver em'grupos, que são formados pelos mais diversos critérios! idade, hábitos ế atitudes, profissão, e assim por diante. Podemos marcar nossa identidade pela afinidade a certos grupos sociais ou a grupos regionais. Os membros desses grupos compartilham características e afinidades, traços de identidade, e, dentre eles, marcas linguísticas.
}

Figura 10 Texto 2 - piloto leitura silenciosa em português

Fonte: Dados de pesquisa.

Os movimentos sacádicos, no entanto, não foram contabilizados nesse estudo. As regressões foram identificadas para se quantificar e tirar a média que serão somadas e divididas pela média aritmética. Essa média será a quantificação de 
cada texto, isto é, o mesmo texto para todos os participantes dos experimentos. Vale ressaltar que foram aplicados os testes em 19 participantes dentre as três categorias (jovem, envelhescentes e da terceira idade), mas os resultados apresentados não se referem a todos os 19 participantes, dois experimentos foram descartados na análise final devido às inconsistências no desempenho dos testes. Assim, foram considerados 17 testes.

O descarte dos testes se deve a inconsistências de ocorrências, como uso de grau em óculos, cirurgia de catarata e também alguma maquiagem nos cílios. Ainda que previamente avisados, alguns participantes ignoraram as solicitações.

A partir do que é evidenciado na literatura, as palavras de fixação e ou regressão deverão ser as palavras que tenham duplicidade de letras, encontros consonantais, encontros vocálicos e palavras verbais, baseadas em Rayner (1998), Vonk e Cozijn (2003), e palavras de difícil pronúncia. As regressões que acontecem na mesma linha e outras possíveis ocorrências que aparecem nos registros como outras linhas não podem ser consideradas. Só foram considerados os textos que apresentaram maior número de regressões que outros.

Os resultados do Gráfico 6 se referem aos 17 dos 30 participantes cujo movimento ocular conseguimos registrar. Foram descartados os registros que apresentaram falta de linearidade de leitura e falta de fixações e regressões para selecionar dois experimentos das três categorias.

Nas análises feitas sobre o número de regressões, não houve diferença significativa em nenhum dos grupos estudados. Houve muitas dispersões de leitura entre as linhas verticais. A ausência de um estudo de compreensão impede que se façam explanações além da constatação acima, o que aponta para um campo de pesquisas futuras ([ANOVA para os textos em Português: $\mathrm{F}_{(2,92)}=0,774, \mathrm{P}=$ 0,$464 ; \mathrm{F}_{(1,92)}=0,750, \mathrm{P}=0,389$ ]; [ANOVA para os textos em Inglês: $\mathrm{F}_{(2,81)}=0,294$, $\left.\left.\mathrm{P}=0,7458 ; \mathrm{F}_{(2,81)}=4,307, \mathrm{P}=0,0411\right]\right)$.

\subsection{TEMPO PLANEJADO E TEMPO EXECUTADO DAS AULAS}

Ainda considerando a dimensão cognitiva, mas também a dimensão social do tempo, realizamos um estudo sobre a organização do curso, em relação ao tempo planejado e ao tempo executado de cada aula, considerando as evidências apontadas na literatura em relação à execução de tarefas e o dispêndio de tempo por parte dos idosos (o que foi confirmado, de certo modo, no estudo de leitura). Nossa hipótese é de que as aulas demandam mais tempo do que o planejado. Para identificar em que momentos há maior demanda de tempo, as aulas foram segmentadas em atividades e o tempo, aferido para cada uma das atividades. 


\section{$\boxminus$ Leitura Voz Alta $\boxminus$ Leitura Silenciosa}

(A)

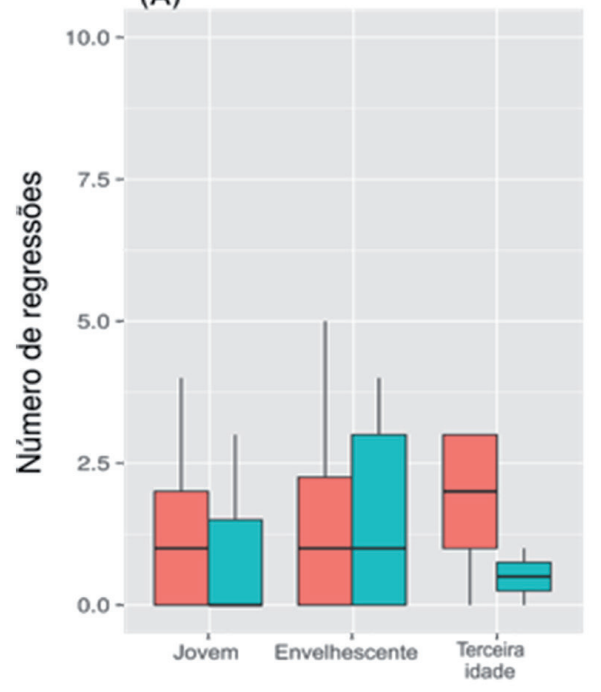

(B)

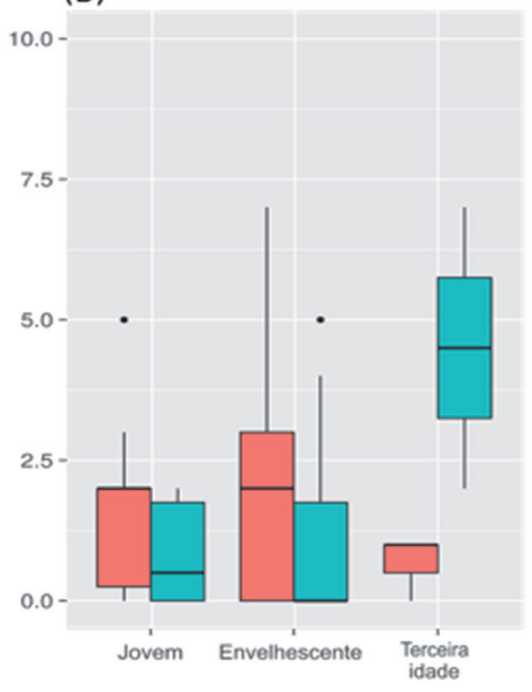

Grupos experimentais

Gráfico 6 Número de regressões em função dos grupos experimentais (A) português e em (B) inglês

Fonte: Dados de pesquisa.

Os relatórios do ministrante e as fichas de acompanhamento de cada uma das aulas foram analisadas e tabuladas, a fim de conferir cada registro que foi feito durante a coleta de dados, tanto do tempo como dos passos das aulas. A rotina de classe das aulas do projeto era composta por dez atividades as quais denominamos no Quadro 4.

Quadro 4 Atividades que compõem a aula

\begin{tabular}{|l|}
\hline A1 - Aplicação teste emocional \\
\hline A2 - Verificar ativ. Aula anterior \\
\hline A3 - Reprodução do vídeo da lição \\
\hline A4 - Explicação de vocabulário e funções indutiva no texto \\
\hline A5 - Leitura em voz alta e ou silenciosa dos textos \\
\hline A6 - Revisar estruturas da língua etc. \\
\hline A7 - Atividade extra e ou lúdica (música) \\
\hline A8 - American x Brazilian Culture \\
\hline A9 - Aplicar teste emocional \\
\hline A10 - Coffee Break \\
\hline
\end{tabular}

Fonte: Dados de pesquisa. 
O tempo de cada atividade foi medido e está sistematizado nos Gráficos 7 e 8 , respectivamente, turma 1 e turma 2 .

Nos Gráficos 7 e 8, relativos ao tempo planejado e executado do grupo das aulas, a linha grossa representa a não variação no tempo planejado e executado, a exemplo das atividades A2, A3 e A4. A identificação entre o quadro verde significa que houve uma mudança no tempo da atividade A6.

$\mathrm{Na}$ turma 1, ao analisarmos o levantamento do tempo das atividades das aulas planejadas e executadas, podemos observar que basicamente não houve diferença no tempo das aulas planejadas, mantendo-se o planejamento para se ministrar as atividades de rotina de classe. Em trinta encontros de aulas ministradas, de março a junho de 2016, a média de cada aula planejada resultou em 136,6 min. Embora as aulas executadas apresentem uma média de 135,2 min para a turma 1 , nos desmembramentos dos dias das aulas, as atividades de aplicação de teste emocional (A1), verificação das atividades das aulas anteriores (A2), explicação de vocabulário indutiva no texto (A4), atividades extras (A7) e coffee break (A10) sempre ultrapassaram o tempo planejado, o que sugere a necessidade de um de preparo diferenciado dos alunos-professores para saber lidar com o público específico. Do ponto de vista estatístico, a realização de um teste-t entre os tempos de aula planejado e executado para a turma 1 aponta para diferenças significativas entre o tempo planejado e o executado nas atividades A1, A4, A5, A7 e A10 (A1: $\mathrm{t}_{(29)}=4,89, \mathrm{P}<0,005^{12}, \mathrm{~A} 2: \mathrm{t}_{(29)}=0,1419 ; \mathrm{P}=$ $0,888, \mathrm{~A} 3: \mathrm{t}_{(29)}=0,04516 ; \mathrm{P}=0,9643 ; \mathrm{A} 4: \mathrm{t}_{(29)}=-3,1924, \mathrm{P}=0.003^{12} ; \mathrm{A} 5: \mathrm{t}_{(29)}=$ $-2,4667, \mathrm{P}=0,01988 ; \mathrm{A} 6: \mathrm{t}_{(29)}=-1,0357, \mathrm{P}=0,3089 ; \mathrm{A} 7: \mathrm{t}_{(29)}=-4,3537, \mathrm{P}=$ 0,$000152 ; \mathrm{A} 8: \mathrm{t}_{(29)}=0,8101, \mathrm{P}=0,42245 ; \mathrm{A} 9: \mathrm{t}_{(29)}=-0,62127, \mathrm{P}=0,5393 ; \mathrm{A} 10$ : $\left.\mathrm{t}_{(29)}=7,9629, \mathrm{P}<0,005\right)$, com valor de alpha utilizado 0,005, usando o ajuste de Bonferroni.

Já para a turma 2, com apenas 15 encontros de aula, também planejados, resultou em uma média de 116,6 min de aula. A realização de um teste-t entre os tempos de aula planejado e executado para a turma 2 apontou para diferenças significativas entre o tempo planejado e o executado nas atividades A5, A6 e A8 $\left(\mathrm{A} 1: \mathrm{t}_{(29)}=1,6425, \mathrm{P}=0,1244, \mathrm{~A} 2: \mathrm{t}_{(29)}=-1,1991 ; \mathrm{P}=0,2519, \mathrm{~A} 3: \mathrm{t}_{(29)}=-0,66892\right.$; $\mathrm{P}=0,5153 ; \mathrm{A} 4: \mathrm{t}_{(29)}=0,62804, \mathrm{P}=0.5409 ; \mathrm{A} 5: \mathrm{t}_{(29)}=-2,2948, \mathrm{P}=0,03904 ; \mathrm{A} 6$ : $\mathrm{t}_{(29)}=-2,2762, \mathrm{P}=0,0404 ; \mathrm{A} 7: \mathrm{t}_{(29)}=-1,0481, \mathrm{P}=0,3137 ; \mathrm{A} 8: \mathrm{t}_{(29)}=2,5135, \mathrm{P}=$ 0,$\left.02592 ; \mathrm{A} 9: \mathrm{t}_{(29)}=-1, \mathrm{P}=0,3356\right)$.

Lembramos, no entanto, que, na turma 2, embora os alunos sejam considerados da terceira idade (4 alunos apenas), eles dispensaram o coffee break (que é o momento de interação social), por serem bastante ativos ainda no seu tempo 
social de vida, atuando no mercado de trabalho, embora oficialmente aposentados. Outra observação para essa turma é que os alunos sempre chegam posterior ao horário de início da aula devido ao trânsito. No entanto, são assíduos e demonstram participação ativa na aula pelo tempo maior nas verificações das atividades das aulas anteriores (A2) e também na explicação de vocabulário e funções indutivas no texto (A4) e nas discussões de cultura brasileira e americana do item A8, evidenciando, assim, sua participação ativa, mas com necessidade de um tempo maior para responder as atividades executadas.

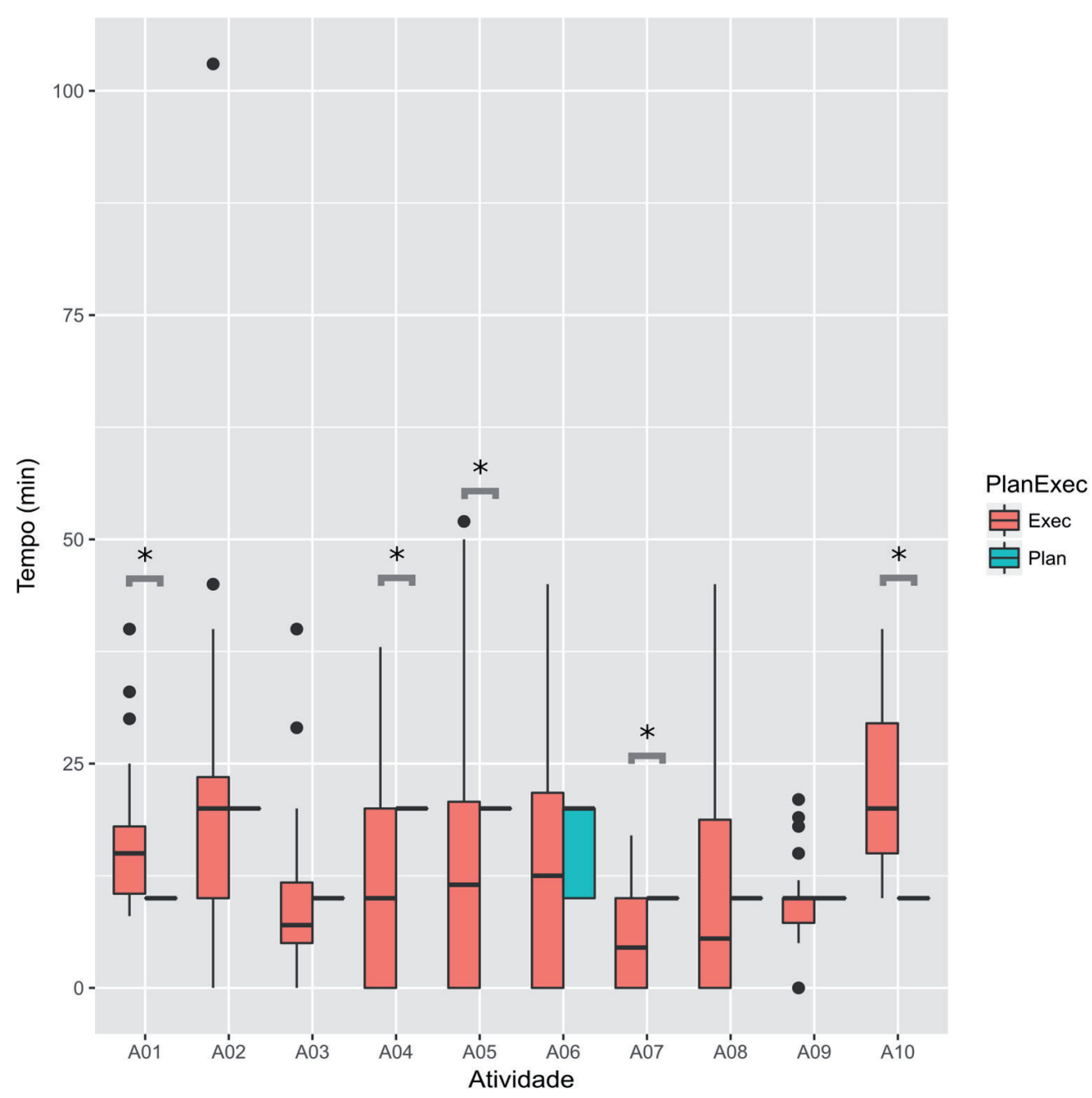

Gráfico 7 Tempo de duração de cada atividade - Turma 1

Fonte: Dados de pesquisa. 


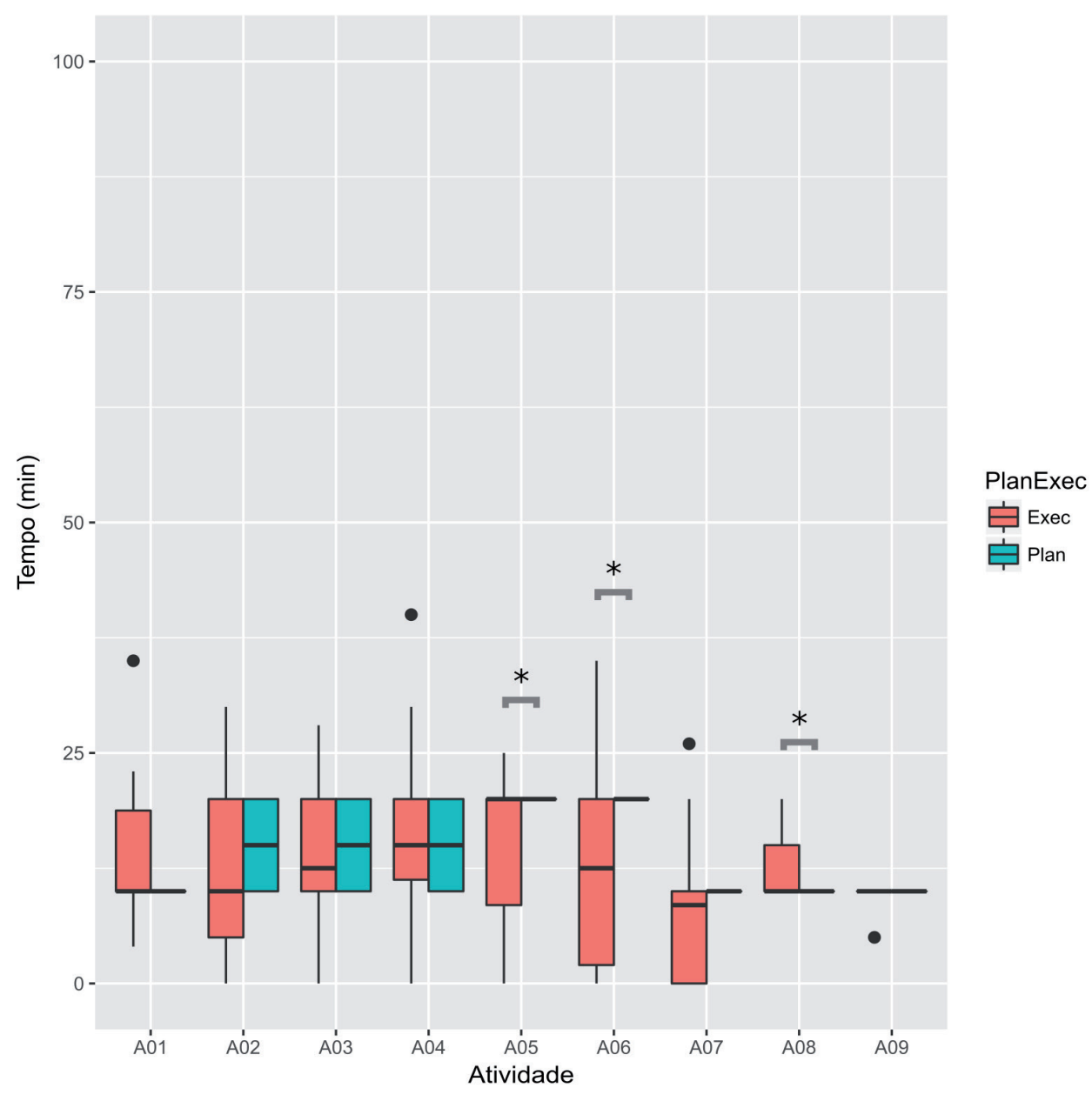

Gráfico 8 Tempo de duração de cada atividade - Turma 2

Fonte: Dados de pesquisa.

Considerando nossa hipótese de que o tempo executado seria maior do que o planejado, os dados empíricos evidenciam que não houve a sua corroboração: o tempo global de execução, em ambas as turmas, foi inferior ao tempo planejado. Isso sugere que o planejamento das aulas sofre efeitos de estereótipos relacionados ao envelhecimento, de que idosos são mais lentos, por exemplo (VIEIRA; LIMA, 2015). Analisando as atividades, constatamos que as que demandaram mais tempo do que o planejado foram, além das aulas de revisão, as que têm cunho social, como as fichas emocionais e o coffee-break. Esses resultados sugerem que as atividades de socialização precisam ser consideradas com maior tempo, mas as atividades de cunho pedagógico, não. De certa forma, os resultados se alinham ao que foi constatado no estudo de leitura: embora demandem mais tempo para a 
execução de tarefas, como foi evidenciado, a diferença não interfere em uma aula, e isso faz com que o planejamento seja superdimensionado, muitas vezes por estereótipo e preconceito, como apontam Vieira e Lima (2015).

\subsection{MOTIVAÇÃO PARA A AULA}

Considerando que o lócus da pesquisa é um curso livre para participantes que não são obrigados a frequentá-lo (diferentemente de um público da faixa etária de escolarização obrigatória, por exemplo), nossa hipótese para aferirmos o estado emocional é de que ele é predominante positivo. Ao aferir as emoções na entrada e na saída, como apresentamos na metodologia, em cada aula documentada, visamos a identificar se o curso instiga mudanças emocionais em seus participantes.

Durante o período de coleta de dados, alternadamente, aplicamos 5 modelos diferentes de testes emocionais, o que denominamos de "fichas emocionais", cujo objetivo foi permitir avaliar o estado de espírito de cada aluno. A estratégia visava a deixar os participantes das aulas do curso de extensão descontraídos, sem que eles percebessem que estavam sendo analisados pela motivação e por seu estado emocional através das figuras nos variados modelos dos testes apresentados. As palavras possuíam funções adjetivas que revelavam estado de motivação em cada desenho para ser marcado por cada participante. Do ponto de vista pedagógico, as fichas emocionais auxiliaram em atividades de ampliação do vocabulário, já que houve a oportunidade de trabalhar com os alunos os significados das palavras adjetivas em inglês e também de justificar por escrito suas opções de respostas abertas, o porquê da resposta.

Para fins de análise dos dados, fizemos o desmembramento dos participantes: Turma 1, com 30 aulas documentadas, ministradas nas segundas e quartas-feiras, contando com 15 alunos, 8 envelhescentes e 7 participantes da terceira idade.

A turma 2, com 15 aulas documentadas, ministradas nas sextas-feiras, com apenas quatro alunos, que denominamos de terceira idade.

Dos dezenove alunos participantes do curso de extensão, das turmas 1 e 2 , dois eram do gênero masculino da terceira idade (aposentados - um motorista de caminhão, o outro comerciante); os outros 7 participantes da terceira idade eram do gênero feminino, eram aposentadas (comerciantes, professoras universitárias, fisioterapeuta, bancária, costureira, dona de casa). Dos 8 envelhescentes, todos do gênero feminino, eram ativas no mercado de trabalho (professora do ensino médio, funcionária pública e donas de casa).

Os participantes recebiam na entrada das aulas as fichas emocionais e permaneciam com elas até a saída, quando entregavam as fichas ao ministrante e ou 
documentador antes de saírem das aulas. Os alunos foram instruídos que poderiam marcar com X ou pintar com lápis de cor oferecido a todos na aula.

Após a tabulação das fichas, os dados foram submetidos ao tratamento estatístico, visando a identificar a motivação, no início da aula, e satisfação dos alunos após a aula.

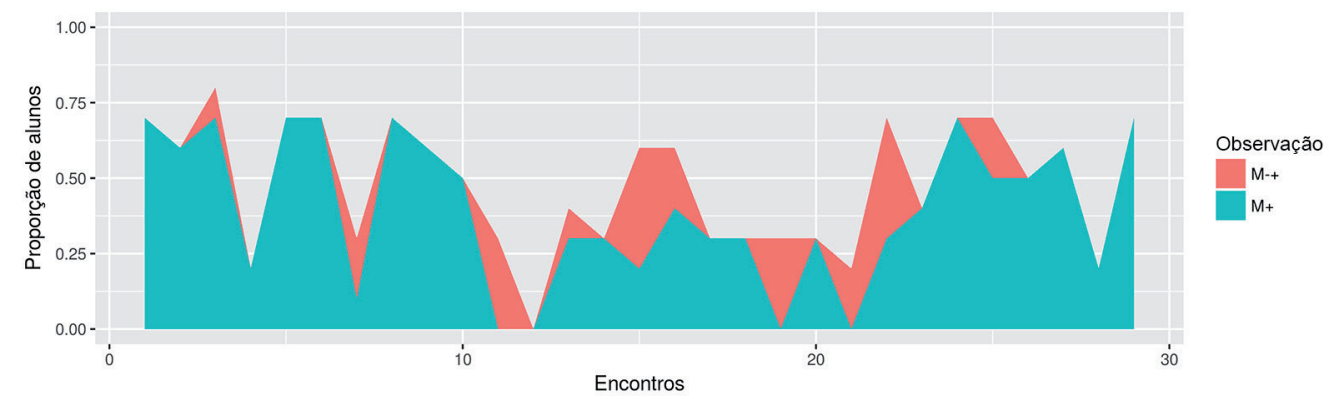

A área vermelha representa a proporção de mudanças emocionais tanto positivas quanto negativas (M+-). A área azul representa a proporção de mudanças positivas $(\mathrm{M}+)$.

Gráfico 9 Testes emocionais dos participantes da terceira idade - Turma 1 (seg/qua) Fonte: Dados de pesquisa.

Como podemos ver no Gráfico 9, os participantes da terceira idade apresentam um grau de satisfação superior ao de insatisfação. No entanto, a presença de insatisfação está relacionada a problemas de ordem pessoal como dores, problemas familiares, falta de estacionamento para colocar o carro ou no dia de aula que tinha diversas explicações sobre funções gramaticais.

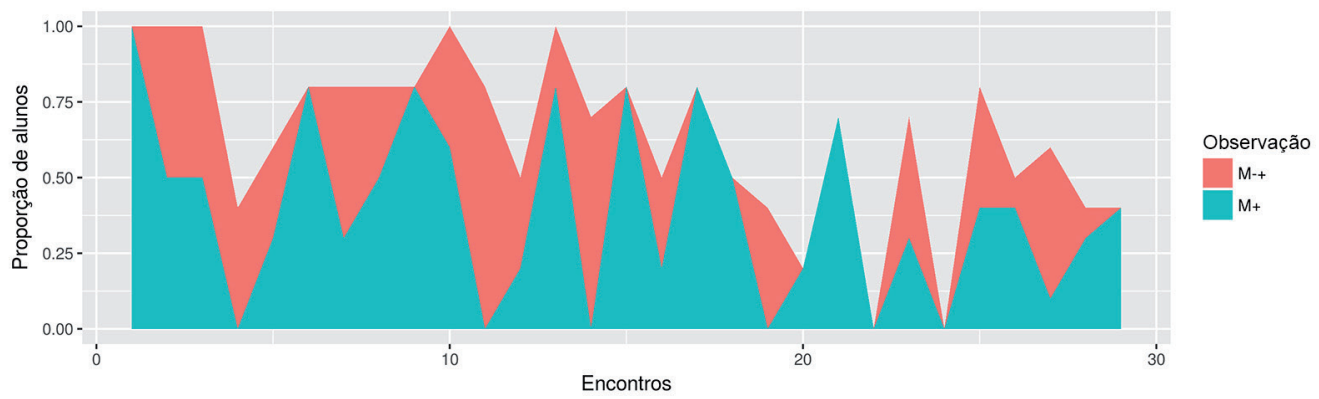

A área vermelha representa a proporção de mudanças emocionais tanto positivas quanto negativas (M+-). A área azul representa a proporção de mudanças positivas $(M+)$

Gráfico 10 Testes emocionais dos participantes envellhescentes - Turma 1 (seg/qua) Fonte: Dados de pesquisa. 
O Gráfico 10 ressalta a continuidade de grau de satisfação dos envelhescentes em relação às mudanças negativas. Eles também tiveram os mesmos problemas que o grupo da terceira idade: problemas de ordem pessoal como dores, problemas familiares, falta de estacionamento para colocar o carro ou no dia de aula que tinha diversas explicações sobre funções gramaticais.

Observa-se, no entanto, que o grau satisfação aumenta no momento do coffee break, em que eles compartilham experiências e uso da aprendizagem adquirida nas aulas, a exemplo dos role plays. Como é um momento de sociabilização, é imprescindível compartilhar esse momento entre envelhescentes e participantes da terceira idade. Ressalte-se, inclusive, que eles já ressignificaram suas vidas ampliando o nível social em outros dias de encontros extraclasse, fazendo, assim, um novo ciclo de amizade e aprendendo a viver e experienciar a terceira idade.

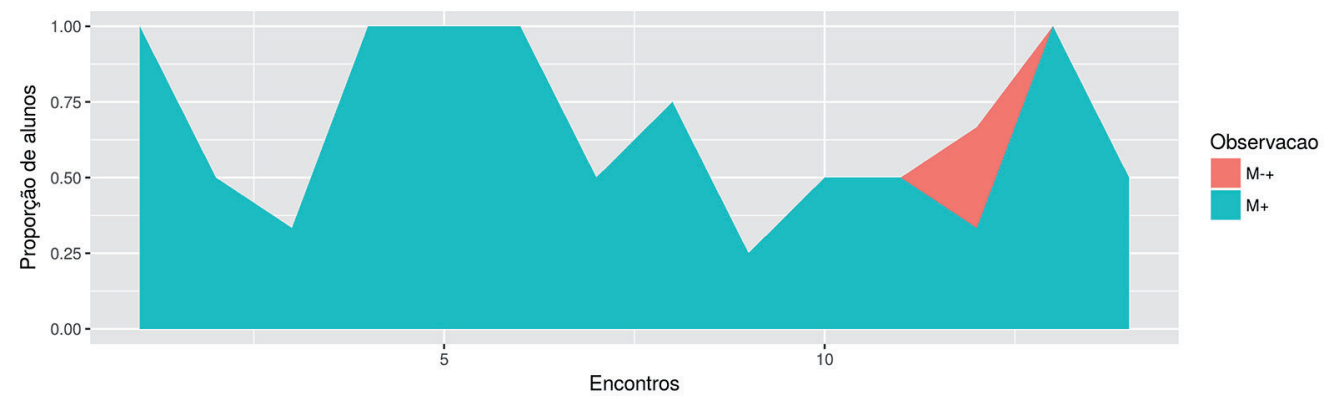

A área vermelha representa a proporção de mudanças emocionais tanto positivas quanto negativas $(\mathrm{M}+-)$. A área azul representa a proporção de mudanças positivas $(\mathrm{M}+)$

Gráfico 11 Testes emocionais dos participantes da terceira idade - Turma 2 (sex) Fonte: Dados de pesquisa.

Já na turma 2, embora tenha como objetivo o mesmo da turma 1 - aprender a língua estrangeira -, a motivação não é igual, mas o grau de satisfação é preponderantemente positivo. A turma 2, por seus componentes serem apenas quatro alunos e por ainda estarem na fase laboral após a aposentadoria, eles participam das aulas pelo desejo de aprender um idioma, consciência sobre o bem cognitivo que todos possuem, bem como fazer parte de várias viagens internacionais e acesso à internet. E também leitura em artigos científicos. A mudança negativa é também por falta de estacionamento ou por problema pessoal (saúde e família).

Foi realizada uma correlação não paramétrica pelo método de Kendall entre a linha que representa as mudanças (tanto negativas como positivas, $\mathrm{M}+-_{+}$) e a linha que representa as mudanças positivas $(\mathrm{M}+)$. Os resultados obtidos apontam que, para a turma 1 , envelhescentes, a correlação foi de 0,581 significativa ( $\tau$ de Kendall $=0,5817, \mathrm{P}<0,001)$ e para a terceira idade dessa mesma turma, a corre- 
lação foi de 0,795 significativa ( $\tau$ de Kendall=0,79578, $\mathrm{P}<0,001$ ). Por outro lado, na turma 2, a correlação foi de 0,919 significativa. Em todos os casos, a significância foi inferior a $\tau$ de Kendall $=0,05$ ( $\tau$ de Kendall $=0,91947, \mathrm{P}<0,001$ ).

Em suma, os resultados da aplicação das fichas emocionais apontam que, de maneira geral, os participantes têm uma atitude positiva em relação ao curso, tanto na entrada como na saída (happy, hopeful, confident, surprised, smile, pleased, laughing). Nos dias em que a atitude de entrada foi negativa no teste de saída (angry, dejected, hungry, shy, confused, sad, disappointed), houve a mudança para atitudes positivas (happy, determined, hopeful). Esse comportamento pode ser explicado pelo fato de haver intervalos entre as aulas para o coffee break, quando os alunos têm a oportunidade de se sociabilizar e desempenhar role plays (reprodução dos aprendizados dos textos das aulas do curso de extensão em inglês). Tais resultados sugerem que a interação social entre os participantes de um curso de língua estrangeira para envelhescentes e pessoas da terceira idade, com as experiências e a sociabilização, pode contribuir para o bem-estar desse público, minimizando riscos de doenças, como depressão e demências do envelhecimento, o que pode ser explorado como uma política pública para a promoção de bem-estar social. 
